\title{
Implementation and Evaluation of 7Es Scientific Inquiry through Plant Assay Guide Manual among Grade 9 Science, Technology, and Engineering (STE) Junior High School Students
}

\author{
Ma. Socorro Gonzaga-Leong-on \\ College of Liberal Arts, Sciences and Education, University of San Agustin, Iloilo City, Philippines
}

Received April 28, 2020 ; Revised May 27, 2020; Accepted July 1, 2020

Copyright $\odot 2020$ by authors, all rights reserved. Authors agree that this article remains permanently open access under the terms of the Creative Commons Attribution License 4.0 International License

\begin{abstract}
The 7Es Scientific Inquiry Through Plant Assay Guide Manual was developed to address the development of science inquiry skills, localization and contextualization among junior high school students. These are some of the requirements of the $\mathrm{K}-12$ science curriculum in the Philippines. However, the developed laboratory manual was not yet implemented and evaluated among the junior high school students. This study was conducted to describe the implementation and evaluation of the developed laboratory manual. In this descriptive research, the respondents were twenty-eight (28) Grade 9 STE students from a public school in a congressional district of the Philippines, school year 2019-2020. During the implementation, five (5) out of eleven (11) procedures in the manual were tried out through a seminar-workshop. The modified evaluation form for Learning Resource Materials (print) from the Department of Education, Philippines and the researcher-made pretest and post-test were used during the evaluation. The results showed that during the implementation, the students actively participated in the seminar-workshop by performing the activities with dedication and enthusiasm. They clarified procedures for them to do the activities correctly. Using the laboratory manual, the knowledge $(z=4.35, p=0.00)$ and skills $(z=3.35, p=0.00)$ of the students on the five biology laboratory procedures implemented significantly increased. The students rated the manual excellent $(M=94.4 \%$, $S D=2.93)$. They gained new knowledge and skills on plant identification and collection, extraction of plant compounds, phytochemical screening, cytotoxicity, and allelopathic activity screening of plant extracts. They were able to create topics using plants for their SIPs. They learned that conducting SIPs needs not to be expensive; one can use common materials and can do improvisations.
\end{abstract}

This study offers a manual that could guide students in the conduct of SIPs.

Keywords 7Es, Laboratory Manual, Plant Assay, Evaluation, Implementation, Bioactivity, Inquiry-based Learning

\section{Introduction}

The core learning standard in the current K-12 science curriculum in the Philippines mandates that high school students' inquiry skills should be developed. The other skills that needed to be developed are their understanding of basic science concepts, scientific attitudes, and values to solve problems critically.

Science inquiry skill can be developed by using the Inquiry-Based Learning (IBL). IBL was credited to John Dewey in 1910. In IBL, students learn to do independent investigations of real-world problems. During investigations, students develop skills in asking questions, think what are needed for them to answer the question, and present what they have discovered to others [1]. It was Dewey who suggested that IBL should be included in the K-12 science curriculum [2]. Since then, inquiry-based approaches to teaching and learning have been used through the years, until this $21^{\text {st }}$ century [3], especially in science education. Conducting Science Investigatory Projects (SIPs) is an approach under IBL.

In K-12 science curriculum in the Philippines, Grade 9 Science, Technology and Engineering (STE) students are required to make proposal of SIPs. This is to address the core learning standard on the development of their science 
inquiry skills. Their SIP proposals must have a clear and focused purpose. These must also identify a contribution to the field of study using scientific methods. Under the design and methodology, their SIPs must have a well-designed plan and data collection methods. The variables and controls must be defined appropriately and completely. If students join contests like the Intel International Science and Engineering Fair (ISEF), they need to satisfy these criteria. All of these are activities under IBL.

The current curriculum for science also calls for contextualization and localization. They must conduct SIPs wherein the students' experiences can relate and the use of available materials in their locality is evident. However, there were several problems encountered by teachers and students in conducting SIPs to comply the requirements of the current science curriculum. One is the lack of laboratory equipment (insufficient) [4]. According to teachers and students, they need to do extra expenditures because they need to look for laboratories outside their schools that require payments. Another problem is the lack of training of teachers and students on laboratory procedures. There is also a lack of manuals/ instructional materials as reference material for the conduct of SIPs. However, it was stressed out that there is a need to let the science students experience laboratory activities. It has a central and distinctive role in science education [5]. Laboratory experiences increase the students' understanding of the science concepts. The application of these concepts can also develop their practical skills. It can also improve problem-solving skills of the students. The understanding of how scientists do their work can also be achieved. More importantly, laboratory works develop interest and motivation among science students [6]. IBL requires the developments of these skills, as well as interest and motivation.

To help solve the problems encountered by teachers and students in the conduct of SIPs, a laboratory manual, Scientific Inquiry Through Plant Assay Guide Manual, was developed following the constructivist's 7Es format (elicit, engage, explore, explain, elaborate, evaluate, and extend) while it addresses the development of science inquiry skills, contextualization and localization. This manual, which significantly increased the knowledge and skills of science teachers, was an output of a conducted research by Leong-on et al. (2018) [7]. In that research, they found out that the science teachers' level of knowledge and skills in selected Biology procedures were very low. These were topics of SIPs for the past 4 years (2014-2018) in a region of the Philippines. The study of Leong-on et al., was conducted among junior high school science teachers in a congressional district of Philippines (2018). In that study, it was recommended that the developed 7Es laboratory manual should be implemented to the students and must be evaluated by them.

With the reasons aforementioned, this study was conducted to describe the implementation and evaluation of the developed manual, Scientific Inquiry Through Plant Assay Guide Manual. The implementation and evaluation were done among Grade 9 STE students who were enrolled for school year 2019-2020 from a public school in a district of Iloilo. The laboratory manual used in the seminar-workshop was effective in improving the knowledge and skills on selected Biology laboratory procedures. The grade 9 STE students who attended the seminar-workshop rated the developed laboratory manual as excellent. It can be recommended for use. The developed laboratory manual can benefit the students, the teachers, the school heads, and the curriculum planners for it can be a guide for SIPs.

\section{Materials and Methods}

\subsection{Research Design}

The study employed descriptive research design. It described the implementation and evaluation of the developed manual, Scientific Inquiry Through Plant Assay Guide Manual.

\subsection{Methods}

\subsubsection{Respondents}

The respondents of the study were the twenty-eight (28) out of the thirty-five (35) grade 9 STE class from a public junior high school in a congressional district of the Philippines for school year 2019-2020. The study used purposive sampling because the respondents were chosen due to their needs to make a research proposal. The respondents were those students who were present, since the participation for the study was voluntary. The school that was chosen had recently opened their STE class.

\subsubsection{Instruments}

One of the instruments used in this study was the set of printed modified evaluation form for Learning Resource Materials (print) from the Department of Education, Philippines. It evaluated the content, format, presentation and organization, and accuracy and up-to-datedness of information (no obsolete information) of the manual. Under the content part of the evaluation, the students were made to identify the desirable values and traits that can be enhanced by the manual. Another instrument used was the researcher-made pretest and post-test with an internal reliability (Cronbach's Alpha) of 0.80 for both knowledge and skills. It was composed of fifteen (15) questions on knowledge and another fifteen (15) questions on skills about the five (5) Biology laboratory procedures in the manual (three questions per procedure). The questions were based on the standard procedures published in 
referred journals.

\subsubsection{Data Collection Procedure}

Permissions from the school principal and the department head of the Grade 9 STE students were secured prior to the implementation (seminar-workshop) of the laboratory manual. The students were requested to sign the informed consent form for their voluntary participation and their rights were also stipulated therein. A pretest was administered prior to the implementation. During the implementation, observations were made and recorded. The post-test and the evaluation form of the Learning Resource Materials were given to the students right after the implementation.

\subsubsection{Implementation}

During the implementation, a seminar-workshop was conducted among the Grade 9 STE students (respondents). Out of eleven (11) procedures in the developed manual, five (5) doable procedures were tried out in a school setting. Based on the students' comments on the five procedures that were tried out, the remaining six procedures were also edited. These procedures included: plant identification and collection, extraction of plant components and phytochemical analysis. Other procedures were the brine shrimp lethality assay for cytotoxicity testing and the allelopathic activity screening of plant extracts. The manual follows the 7Es format, which has an improvisation section. It also has suggestions on how to record the results of the activities. Suggestions to the statistical analysis can also be found. The manual also included a part on how to prepare concentrations of the extracts and chemicals in the different bioactivities. A glossary was an added feature of the manual.

\subsubsection{Evaluation of the Laboratory Manual}

The Grade 9 STE students were requested to answer the pretest and post-test. They were also requested to evaluate the manual using the printed modified evaluation form for Learning Resource Materials from the Department of Education, Philippines. They also wrote their significant learning and realizations.

\subsubsection{Statistical Analysis}

Wilcoxon Ranked Test was used to determine the difference between the pretest and post-test results of the Grade 9 STE students.

\section{Results}

\subsection{Implementation}

During the implementation of the developed laboratory manual, a seminar-workshop was conducted. The result showed that the Grade 9 STE students actively participated in the seminar-workshop. They performed the activities with dedication and enthusiasm. They also clarified procedures for them to do the activities correctly.

\subsection{Evaluation of the Manual}

Using the developed laboratory manual, the knowledge $(z=4.35, p=0.00)$ (Table 1.) and skills $(z=3.35, p=0.00)$ (Table 2.) of the respondents in the five (5) biology laboratory procedures tested significantly increased.

Table1. Pretest and Post-tests Results on Knowledge on Selected Biology Laboratory Procedures among the Grade 9 STE Students from a Public School in a Congressional District of the Philippines

\begin{tabular}{|c|c|c|}
\hline Area of Evaluation & Mean & SD \\
\hline Knowledge & & \\
Pretest & 7.00 & 1.63 \\
Post-test & 10.40 & 1.40 \\
\hline
\end{tabular}

$\mathrm{Z}=4.35, \mathrm{p}=0.00$

Table2. Pretest and Post-test Results on Skills on Selected Biology Laboratory Procedures among the Grade 9, STE Students from a Public School in a Congressional District of the Philippines

\begin{tabular}{|c|c|c|}
\hline Area of Evaluation & Mean & SD \\
\hline Skills & & \\
Pretest & 5.79 & 2.47 \\
Post-test & 9.14 & 1.80 \\
\hline
\end{tabular}

$Z=3.85, p=0.00$

The Biology laboratory procedures in the developed laboratory manual were rated by the Grade 9 STE students in terms of its content, format, presentation and accuracy, and up-to-datedness of information. The students rated the manual as excellent ( $M=94.4 \%, S D=2.93)$ (Table 3.)

Table 3. Students' Evaluation on the 7Es Scientific Inquiry through Plant Assay Guide Manual Using the Modified Evaluation form for Learning Resource Materials (print) from Department of Education, Philippines

\begin{tabular}{|c|c|c|c|}
\hline Areas & Mean Score & Percentage & Description \\
\hline Content (perfect score is 28pts) & 26.20 & 93.57 & excellent \\
Format (72pts) & 69.92 & 97.00 & excellent \\
Presentation (20pts) & 19.28 & 96.4 & excellent \\
Accuracy and Timeliness of information (24pts) & 21.75 & 90.63 & excellent \\
\hline
\end{tabular}

$M=94.4 \%, S D=2.93$

Note:*Passing percentage is $75 \%$. The means were interpreted as follows: $90-100=$ excellent; $85-89=$ good, $80-84=$ average; $75-79=$ fair; 74 and below $=$ poor 


\section{Significant Learning and Realizations}

The Grade 9 STE students who attended the seminar-workshop during the implementation of the laboratory manual acquired new learning. These new knowledge and skills of laboratory techniques include plant identification and collection, extraction of plant compounds, phytochemical screening, cytotoxicity, and allelopathic activity screening of plant extracts. They were able to create topics using plants for their SIPs. They learned that conducting SIPs (researches) needs not to be expensive and that one can use local materials and can do improvisations to carry out SIPs.

\section{Discussions}

The results showed that during the implementation of the laboratory manual through seminar-work shop, the Grade 9 STE students actively participated by performing the activities with dedication and enthusiasm. This can be explained that IBL, credited to John Dewey, raises motivation and scientific concepts understanding among science high school students [8]. Therefore, it is encouraged to be used in schools. Further, an inquiry-based classroom was perceived by middle school students to be more cohesive and a more engaging learning environment [9]. With that being said, the idea that the 7Es model (formerly 5Es), a constructivist instructional strategy to which the Scientific Inquiry through Plant Assay Guide Manual was patterned, can be explained as effective. In one study conducted in a rural school, the 7Es model facilitated students' interests, like in genetics. It was recommended that the 7Es model must bead opted in the school system for teaching biology [10]. The model also had positive significant effect on the achievements and interests in senior secondary science Physics students [11]. The Grade 9 STE students clarified procedures for them to do the activities correctly during the implementation. One of the elements of IBL includes the clarification of procedures (asking questions) by students [12].

The significant increase in the students' knowledge and skills on the selected Biology laboratory procedures can be attributed to the feasibility of the procedures in the laboratory manual. Being an informative manual, it also contributed to the increased knowledge and skills of students. The students can relate procedures in the manual to their previous experiences because of the availability of materials around them and the common procedures they used to perform in their homes. This showed that the developed manual supports what Dewey suggested. He argued that students should connect their new knowledge to their previous experiences [13]. This is in support also of the findings that technical skills, authentic contributions, material type, and the boundaries of the content or familiarity were found as the primary factors affecting the design and development of creative instructional materials
[14]. Students who have learned using the 7Es inquiry based learning achieved higher learning achievements [15]. However, one challenge in conducting SIPs is the lack of instructional materials serving as the guides of procedures in doing experiments. Thus, this study was conducted to provide a laboratory manual that can serve as a guide.

The Grade 9 STE students evaluated that the content of the laboratory manual as suitable for their level of development. It granted the achievement of specific objectives of the subject area and of the year level for which it was intended. The manual was perceived by the students as a tool in enhancing the development of higher cognitive skills such as critical thinking, creativity, learning by doing, inquiry, and problem solving. These are valuable and transferable skills built in IBL [12]. One of the measures of learning quality is the critical thinking skill [16]. The Grade 9 STE students also found out that the manual was free of ideological, cultural, religious, racial, and gender biases and prejudices. The students likewise found out that the laboratory manual can enhance the development of desirable values and traits such as the pride of being a Filipino, honesty, and trustworthiness. Other values that were perceived by the students that can be enhanced by the manual were the positive scientific attitude and reasoning, the ability to distinguish what is right from wrong and the desire for excellence. This is in support of the finding that inquiry-based science camp leads to the maintenance of a more positive attitude towards science. Students who are able to join the camp develop a higher interest in science careers than those who are not able to [17]. Moreover, they found that the laboratory manual can enhance respect and love of country, critical and creative thinking and also encourages helpfulness, teamwork, cooperation, unity and productive work. The laboratory manual was evaluated by students to promote target readers' interest. Adequate warnings or cautionary notes were provided on the activities wherein safety and health are of concern.

The Grade 9 STE students rated the laboratory manual excellent in format. They found out that its font type and sizes are appropriate for the intended users. The spaces between letters and words facilitate reading. The printing is of good quality (i.e., no broken letters, even density, correct alignment, properly placed screen registration). The students also found out that the laboratory manual contains easily recognizable illustrations to clarify and supplement the text. They are properly labeled or captioned and they utilized realistic and appropriate colors that are deemed appropriate and appealing. Furthermore, they recognized the illustrations contextual and relevant because the manual included plants and procedures that can be found in their culture. The students found the design and the layout of the manual to be simple but attractive and pleasing (i.e., does not distract the attention of the reader). There were adequate illustrations in relation to text and elements (e.g., illustrations and text) and are harmoniously blended. The 
laboratory manual catered the needs of the students' difference in visual perceptions. To comply with the students' varied visual needs, this suggests that instructional contents should be displayed in multiple and different forms. [18]. On the paper and binding, the students perceived that the paper used contributes to easy reading and binding. It is durable to withstand frequent use. On weight, the laboratory manual is easy to handle and relatively light.

The grade 9 STE students gave the laboratory manual an excellent rating in presentation and organization. They found that the presentation was engaging, interesting, and understandable. The flow of ideas was logical and smooth. The vocabulary level was appropriate to the target readers' experience and understanding. The length of sentences was suited to the comprehension level of the target readers. Sentences and paragraph structures were varied and interesting to the target readers. The addressing of adolescent readers' knowledge and vocabulary are comprehension needs thus the laboratory manual was created to fit this demand. It must also be engaging the readers in discussion about the text. All throughout the students' experience in reading the manual, the readers must be engaged and motivated [19].

The students also gave an excellent rating on accuracy and up-to-datedness of information. The manual had passed grammatical errors test and computational errors test, and there was no obsolete information. The laboratory manual was also free of conceptual and factual errors. It contained clear illustrations, diagrams, pictures, graphs, and tables.

It is built under IBL that students should communicate their ideas [12]. Thus, the Grade 9 STE students were requested to write their significant learning and reflections. They were able to create topics using plants for their SIPs. SIP is another approach that is framed after IBL, an authentic measure of inquiry skill. This approach significantly improves the integrated science skills of students especially if the SIP is a structure-guided investigation [20]. During the conduct of SIPs, students formulate problems based on their experiences. They also make hypothesis and do investigations. At the end, they acquire evidences that can be used as solutions to real-world problems. There are several challenges, difficulties and threats, however, in developing the science inquiry skills using SIP as an approach to IBL [12]. One challenge is making the students understand the research process by effective mentoring with their teachers [22]. In addition, only a few teachers demonstrate understanding of an open-ended science investigation [23]. Insufficiency of laboratory equipment [4] also hinders the conduct of SIPs as well as lack of training on laboratory procedures.

The findings of this study were limited only among the Grade 9 STE students in one of the districts in Iloilo, Philippines. It was also limited with the use of the evaluation form for printed Learning Resource Materials from the Department of Education, Philippines and the researcher -made pretest and post-test. Different findings may be obtained with different respondents and evaluation instruments used.

\section{Conclusions}

This study was conducted to describe the implementation and evaluation of the developed laboratory manual, 7Es Scientific Inquiry Through Plant Assay Guide Manual. The study used descriptive research method and was conducted in a public school in a district of Iloilo, Philippines. The study revealed that during the implementation, through a seminar-workshop, the students actively participated by performing the activities with dedication and enthusiasm using the developed laboratory manual. They also clarified procedures for them to do the activities correctly. The manual significantly increased the knowledge and skills of the students on selected Biology laboratory procedures. Thus, the manual was effective. The students rated the manual excellent. Therefore, the manual can be recommended for use. They gained new knowledge and skills on plant identification and collection, extraction of plant compounds, phytochemical screening, cytotoxicity, and allelopathic activity screening of plant extracts. They were able to create topics using plants for their SIPs. They learned that conducting SIPs (researches) needs not to be expensive; one can use local materials and can do improvisations. This study offers a laboratory manual that can guide students in conducting SIPs.

\section{Recommendations}

Students can use the developed manual, Scientific Inquiry Through Plant Assay Guide Manual, to guide them in conducting their SIPs. Science teachers and school heads may as well encourage their students to use the manual. Curriculum planners may look into the developed laboratory manual in this study to ascertain if it could serve as a support material in promoting science inquiry skill, contextualization and localization as prescribed K-12 curriculum in the Philippines.

\section{Funding}

This research was funded by the University of San Agustin. The making of the laboratory manual was under the funding of the Science Education Institute, Department of Science and Technology, Philippines.

\section{Acknowledgments}

The study was supported by James Pedregosa, PhD, Academic Supervisor - Education and Nenelyn D. Dela 
Fuente, PhD, Dean, College of Liberal Arts, Sciences, and Education. I express my gratitude to the administrators of the public school where the study was conducted as well as the students who served as respondents. My gratitude is also expressed to Roel Alli, PhD, Peter Ernie Paris, PhD, Lourdes Morano, Ed.D, Elvira Arellano, PhD and Shirley Jusayan, Ed.D who put-in their knowledge and wisdom in my endeavor to make the laboratory manual.

\section{Conflicts of Interest}

The author declares no conflict of interest. The funder had no role in the design of the study; in the collection, analyses, or interpretation of data; in the writing of the manuscript, or in the decision to publish the results.

\section{REFERENCES}

[1] Lee, V.S., Greene, D.B., Odom, J., Schechter, E., Slatta, R.W. (2004). What is Inquiry Guided Learning. In V.S. Lee (Ed.), Teaching and Learning through Inquiry: A Guide book for Institutions and Instructors. Sterling, VA: Stylus Publishing, 3(15).

[2] Barrow, L.H. (2006). Journal of Science Teacher Education, 1(3), 265-278.

[3] Herman, W.E., Pinard, M.R. (2015). Critically Examining Inquiry-Based Learning: John Dewey in Theory, History, and Practice, Inquiry-Based Learning for Multidisciplinary Programs: A Conceptual and Practical Resource for Educators (Innovations in Higher Education Teaching and Learning). Emerald Group Publishing Limited, 3, 43-62.

[4] Bangcaya, P.S., Alejandro, G.J.D. (2015). School-related Factors Contributing to the Delivery Enhancement of the Special Science Program in Western Visayas, Philippines. European Journal of Science and Mathematics Education, $3(2), 177-184$.

[5] Hofstein, A., Lunetta, V.N. (2004). The Laboratory in Science Education: Foundations for the Twenty-First Century. Sci Ed, 88, 28-54.

[6] Hamidu, M.Y., Ibrahim, A.I., Mohammed, A. (2014). The Use of Laboratory Method in Teaching Secondary School Students: A key to Improving the Quality of Education. International Journal of Scientific \& Engineering Research, 5(9), 81-86.

[7] Leong-on, M.S. (2018). Competencies of Junior High School Science Teachers on Selected Biology Laboratory Procedures: Inputs to Instructional Material Development. West Visayas State University, Iloilo City, Philippines.

[8] Silm, G., Tiitsaar, K., Pedaste, M., Zacharia, Z.C., Papaevripidou, M. (2017). Teachers' Readiness to Use Inquiry-Based Learning: An Investigation of Teachers' Sense of Efficacy and Attitudes toward Inquiry-Based Learning. Science Education International, 28, 315-325.

[9] Wolf, S.J., Fraser, B.J. (2008). Learning Environment,
Attitudes and Achievement among Middle-school Science Students Using Inquiry-based Laboratory Activities. Fraser Research in Science Education, 38(3), 321-334.

[10] Agogo, P.O., Naakaa, D.A. (2014). Effects of 5Es Constructivist Instructional Strategy on Students' Interest in Senior Secondary Genetics in Gwer Local Government Area, Benue State, Nigeria. Global Journal of Environmental Science and Technology, 1(2), 15-19.

[11] Akanwa, U.N., Ovute, A.O. (2014). The Effect of Constructivist Teaching Model on SSS Physics Students' Achievement and Interest. IOSR Journal of Research \& Method in Education, 4(1), 35-38.

[12] Bhatt, A.R., Chevrier, S., Ciccarelli, R., Grady, R., Kumari, V., Wong, H. (2008). Choose your own inquiry. University Press of America.

[13] Dewey, J. (2011). Democracy and Education. Milton Keynes: Simon and Brown.

[14] Sendurur, E., Cetin, I., Ersoy, E. (2018). The Design and Development of Creative Instructional Materials: The Role of Domain Familiarity for Creative Solutions. International Journal of Technology and Design Education, 28, 507-522.

[15] Suwananphan, U.; Sonsupap, K. (2017). Comparison of 7Es of Inquiry-based Learning and Problem-based Learning in Learning Achievement, Problem Solving and Learning Attitude toward Science Study of Secondary School Students (Grade8). Journal of Education, Mahasarakham University, 11(3), 220-230.

[16] Alsaleh, N. (2020). Teaching Critical Thinking Skills: Literature Review. Turkish Online Journal of Educational Technology, 19(1), 21-39.

[17] Gibson, H.L., Chase, C. (2002). Longitudinal Impact of an Inquiry-Based Science Program on Middle School Students' Attitudes Toward Science. Sci Ed. 86, 693-705.

[18] Tomita, K. (2017). Visual Design as a Holistic Experience: How Students Engage with Instructional Materials of Various Visual Designs. Pro Quest LLC.

[19] Lupo, S.; Conradi Smith, K.; Strong, J. (2019). "Struggle" Is Not a Bad Word: Misconceptions and Recommendations about Readers Struggling with Difficult Texts. Journal of Adolescent \& Adult Literacy, 62(5), 551-560.

[20] Dela Cruz, J.P.C. (2004). Experiencing Science in a $21^{\text {st }}$ Century Middle School Classroom. International Conference on Advances in Education Technology, 75-78.

[21] Errabo, D.D.R., Cajimat, R.T.; Orleans, Antriman. (2018). Factors Affecting the Implementation of Science Investigatory Projects and Its Implications to the National Science and Technology Fair, Advanced Science Letters, American Scientific Publishers. 24(5), 7885-7889.

[22] Aparecio, M.B.M. Mentoring, Self-Efficacy and Performance in Conducting Investigatory Projects: A Mixed-Method Analysis. Asia Pacific Institute of Advanced Research, 2(2).

[23] Moeed, A. (2013). Science investigation that best supports student learning: Teachers' Understanding of Science. International Journal of Environmental \& Science Education, $8,537-559$. 